\title{
Reverse exchange of healthcare devices: the case of hearing aid equipment in the UK
}

\author{
Dr Rosanna Cole (corresponding author) \\ University of Surrey, Guildford, GU2 7XH, UK \\ r.cole@surrey.ac.uk \\ 01483683642 \\ Dr Claire Frances Lindsay \\ Edinburgh Napier University, Edinburgh, EH14 1DJ \\ c.lindsay2@napier.ac.uk \\ 01314554323 \\ Dr Fiona Barker
}

Windsor Audiology Centre, Princess Margaret Hospital, Windsor, Berks SL4 3SJ

fiona.barker@windsor-ent.co.uk

01753206117 


\begin{abstract}
Reverse exchange (RE) in dealing with the return, recycle and reuse of products is receiving a growing focus. When properly handled, RE in healthcare can deliver an economic benefit of cost minimisation and has extensive positive impacts on both human health and the environment ( $\mathrm{Li}$ and Olorunniwo, 2008) but to date, $\mathrm{RE}$ research is mostly limited to pharmaceutical return. This paper investigates the potential for RE benefits in the UK National Health Service (NHS) supply chain for medical devices. Hearing aids supplied to adults with hearing loss are used as an illustrative example. This research applied a consensus approach through the use of dispersed nominal groups in order to obtain qualitative data on information, barriers, solutions and priorities to support findings. Findings illustrate that the end user behaviour of returning the device, and the requirement by NHS Procurement for manufacturers to meet RE targets are secondary to the importance of audiology departments who have the autonomy to design RE processes and successfully implement initiatives. A schematic highlighting the information and materials flow of the supply chain and the barriers and facilitators to RE is presented for hearing aid devices with potential for transferability to other small medical device supply chains.
\end{abstract}

Keywords: Healthcare, reverse exchange, dispersed nominal groups, supply chain 


\section{Introduction}

Sustainable procurement for the public sector and importantly in healthcare has been high on the government's agenda throughout the $21^{\text {st }}$ century (DEFRA 2007; National Audit Office, 2013). In 2006, the Sustainable Procurement Task Force which sits within the Department of Environment, Food and Rural Affairs (DEFRA) provided a definition of sustainable procurement as being:

a process whereby organisations meet their needs for goods, services, works and utilities in a way that achieves value for money on a whole life basis in terms of generating benefits not only to the organisation, but also to society and the economy, whilst minimising damage to the environment (Procuring the Future, 2006:10).

The aim of this strategy is to configure public sector and government supply chains which focus on low carbon, low waste and water efficiencies, to deliver sustainable development objectives (DEFRA, 2007). In the private sector and predominately the manufacturing arena, the role of supply chains in managing sustainable development have been facilitated by reverse exchange (RE) (Schenkel et al., 2015).

The definition of RE includes product design and the product life cycle, encompassing all supporting products in the systems including packaging as well as the 'reverse flow' or recovery processes which include the collection of materials for recycling and disposal, commonly associated with reverse logistics (RL) (Rogers and Tibben-Lemke, 1999; Govindan, Soleimani and Kannan, 2015). RL is commonly more discussed in the literature with RE being a relatively new concept in supply chain management (SCM) 
that encompasses recovery of the item and usually an exchange element. Reverse flow literature has focused on manufacturing based supply chains utilising the lens of RE (recovery, reuse, repair, recycle) to gain performance improvement in product flows (Esain et al., 2016). In these industrial settings, RE is regarded as an effective competitive tool (Chan and Chan, 2008).

In healthcare, RE research is mostly limited to pharmaceutical return (Ritchie et al., 2000; Xie and Breen 2012, 2014). In the UK National Health Service (NHS) device return, focus is more often on high value or high risk device return ( $\mathrm{DoH}, 2012)$ however this can be expanded to smaller, more common devices to realise benefits. Options for upstream entry back into the supply chain for devices, which include replacement, repair (or maintenance) or proper disposal can deliver economic benefit and a positive impact on the environment ( $\mathrm{Li}$ and Olorunniwo, 2008). Esain et al. (2016) were the first to provide extended literature outlining guidance to public service managers (specific to healthcare) to deploy and manage REs.

Enhancing RE in healthcare supply chains is an important step to improving sustainable processes for an economically stretched public service. Providing insights into implementation issues of RE advances knowledge to a point where insights from other reverse flow processes can be applied and practioners can overcome barriers to the execution of returning devices. Additionally, the lack and inconsistency of legislation on the reuse of devices is problematic for RE in healthcare.

Consequently, this paper investigates the potential for RE benefits in the UK NHS supply chain for medical devices. Hearing aids supplied to adults with hearing loss are used as 
an illustrative example. These devices were chosen because high numbers are in circulation and regular checkups with a healthcare professional make them suitable for monitoring for return. Hearing aid RE can be generalised to other devices that are issued to one patient for their lifetime or the life span of the device, such as insulin pumps, asthma inhalers or walking frames. Thus both the process design and refinement and the stakeholder involvement, engagement and coordination is transferable. Insights are sought for one type of medical device to ensure a practical and valuable focus on real facilitators and barriers to implementation by directly studying the supply chain actors involved in the provision of the devices.

The research questions (RQs) are:

- What are the barriers to RE for hearing aid devices in the NHS?

- What are the strategies for overcoming these barriers?

- How would a RE process be most effectively implemented for hearing aid return in the NHS?

\section{Literature Review}

\subsection{Reverse Exchange}

A growing focus has been placed on RL of which RE is a part, to realise economic and environmental gains, for example in the automobile repair sector, electronics industry and packaging industries. Reverse flow can include recovery, remanufacture, refurbishment, replacement, maintenance, reuse, repair, recycle or disposal. A combination of Defee et al,'s (2010) reverse SCM definition and Esain et al.'s (2016) RE explanation are used to 
define RE for this paper as the effective return of a product in order to either dispose of it or recover value, while preserving previous met service expectations and delivering economic and environmental benefit. In healthcare, reverse flow research is mostly limited to pharmaceutical return (Ritchie et al., 2000; Xie and Breen 2012, 2014) because of issues with unused medicines in the public domain and need for incineration. Xie et al. (2016:194) define RE of medical devices as occurring

when products are returned to source for exchange or final recovery due to product replacement (based on patient needs changing), product maintenance (the functionality of the product parts need to be checked or repaired) or obsolescence (product reaches its natural end of life).

RE activities can affect and are affected by stakeholders such as customers or users, governmental organisations, non-governmental organisations, suppliers or other actors in the supply chain of the firm. Thus, considering different stakeholders in RE value research is important (Schenkel et al., 2015). Through the development of reverse supply chain literature, the existing traditional supply chain allows the exploitation of waste to be transformed to resources that can be used again through sustainable activities, such as reusing and recycling (Shaharudin et al., 2017). Among the effectiveness that could be realised by firms, they include cost savings in operations, improving the relationships with customers to encourage repeat use, utilising the recovered products to support the production capacity, lowering the buying cost for raw materials, components or subassemblies because less are needed, mitigating the volume of wastes for disposal, increasing the commitment towards green practices and reducing the scrap rate (Shaharudin et al., 2017). Being a traditional reverse approach, RL now gives way to 
closed loop supply chains (CLSC) and RE which has a reverse restorative/regenerative focus (Batista et al., 2018). But firms do not always exploit the potential of reverse flow as the conditions allowing the exploitation remain unclear (Larsen et al. 2018). Initiatives such as the reuse and advantages of transit stock items in logistics e.g. returnable transport packaging (Yusuf et al., 2017) and CLSC literature outside of the public sector, provide a setting for both yielding economic benefits and meeting customer demand for a product. The technology capabilities, operational models and associated motivation for the success is relevant, especially where inventory management and logistics (certainly not reverse flow) is not the core mission of the NHS but have drawn attention and investment as they affect service levels and costs (Baffo et al., 2009).

RE incorporates issues such as uncertain timing and quantity of returns, disassembly of returned products and the requirement for a RE network (Junior and Filho, 2012). For example, specific information systems supporting partner collaboration are needed in a reverse flow supply network (Ferguson and Browne, 2001). RE as a research area is well served in manufacturing contexts but lacks non-manufacturing perspectives (Kumar et al., 2016) and public service insights (Esain et al., 2016). Remanufacturing as part of RE lacks practical research and Junior and Filho (2012) found mostly theoretical studies in their review of the literature. Xie et al. (2016) and Breen, Xie and Cherrett (2016) have the most pioneering papers on RE of medical devices so far with a limited number of other studies for specific types of equipment such as wheelchairs (Chouinard et al., 2009). Traditionally, many manufacturers approach towards used or end-of-life products was to ignore them (Thierry 1995), but RE opens up new possibilities, opportunities and challenges. The public sector has a responsibility to be leading by example, so even though the recovery value is a major factor in the economic feasibility of the CLSC 
(Abdallah, Diabat and Simchi-Levi, 2012), there are other benefits to be realised outside of economic gains.

There is an expectation that the progression made with hearing aid devices will be scalable to other items with similar characteristics, such as healthcare devices that must be returned before reissue, but also for items which do not need reissue such as crutches for short-term ailments, using process improvements and behavioural influences. Research into private sector reverse flow is useful for this in two ways. Firstly, where the bi-directional nature of service supply chains whereby providers not only need to handle reverse flows in case of service failures, but also when the service is correctly delivered ie. they need to get used items back such as in the case of telecommunications equipment (Kumar et al. 2016) could be useful to emulate for the NHS. Secondly, where complex supply chains are being investigated for items that have been customised online and then returned (Batarfi, Jaber and Aljazzar, 2017).

\subsection{The NHS Context}

When examining the potential for RE, consideration of the healthcare context is important (Radnor and Noke, 2013). In this NHS context, it is difficult to separate the NHS at its inception, to that of today, when viewed in headlines over the years. Insufficient calculations had been made on the NHS budgets requiring more funding, demand was rising, and improvements were required and these issues have been on-going (Klein, 2013). Funding variations, government initiatives, restructuring, accusations of poor quality of care and crisis have appeared to engulf the NHS over the last 70 years. Many of the calls made at the start of the NHS, and over subsequent years, such as the need for 
quality of care, efficiencies and productivity, are still being made (Klein, 2013; Dunn, McKenna and Murray, 2016).

There is an ongoing pressure for the NHS to save money through a combination of cost cutting, productivity improvements and innovation in service delivery in the context of new commissioning structures developing as a result of the Health and Social Care Act 2012 (Sanderson et al., 2015). Procurement has received an enhanced focus in recent years in the NHS where evaluation of service options, configuration, delivery, refinement, integration and the discussion of new pathways is in evidence (NHS Commissioning Board, 2012). Despite this focus, by 2016, the publication of the Carter Review was still critiquing NHS productivity and illustrated the potential for procurement to contribute to an estimated $£ 5$ billion in savings expected each year by the period 2020/21 (Gov.UK, 2016). A key element of the Carter Review focused on procurement and the need for savings but within the report there is no consideration of reuse or recycle and building this mechanism into supplier agreements.

NHS Trusts spend around $£ 9$ billion on the procurement of goods and services and $£ 6$ billion is spent within the acute sector with the breakdown of spending being $1 / 3$ on common goods and services, $1 / 3$ on medical consumables and $1 / 3$ on high cost medical devices (Gov.UK, 2016). A new approach to the purchase of expensive medical devices is required as a figure of $£ 500$ million is given for spend on devices such as implantable heart defibrillators, bespoke prosthetics and bone-anchored hearing aids (NHS England, 2016). Potential expected savings from the Carter Review, estimated out of the $£ 5$ billion per annum expected savings, $£ 1$ billion could be saved through enhanced procurement activities, although a figure of $£ 770$ million is perceived to be more achievable (Gov.UK, 
2016). The challenge for commissioners is to decide where those savings will be derived from.

\subsection{Importance of Audiology Provision in the UK}

Although hearing aids have been available for free on the NHS since its inception in 1948, a number of commissioning groups as a result of pressure on NHS budgets and spending, have proposed cuts to spending on hearing aid devices, despite these devices being the only option for those with hearing loss (Action on Hearing Loss, 2016). These proposed cuts have fuelled newspaper headlines decrying NHS cruelty (Campbell, 2015) and the fuelling of a dementia epidemic (Knapton, 2016).

Hearing loss is estimated to affect 10.7 million adults in England and delays in identifying, diagnosing and managing hearing loss can have a significant impact on the health and well-being of those affected (NHS England, 2011). Loneliness, social isolation and dementia are associated with hearing loss. There is expected to be a rise in those affected by hearing loss due to ongoing global conflict affecting military service personnel, an aging demographic and the use of personal devices (Monitor, 2015). The cost to the UK economy due to lost output is estimated at $£ 25$ billion by the International Longevity Centre UK (ILC, 2014). The World Health Organisation (WHO) estimate that 360 million people worldwide are affected by disabling hearing loss, with resulting costs (including labour and output losses) of 750 billion international dollars ${ }^{1}$ which does not include the cost of hearing devices (WHO, 2017).

\footnotetext{
${ }^{1}$ WHO (2017) define an international dollar as that which would buy in any cited country a comparable amount of goods and services a U.S. dollar would buy in the United States.
} 


\subsection{Return of Devices in the NHS}

Although there is evidence of pressures to reduce NHS budgets for devices such as hearing aids, the societal and health implications of these decisions means that alternatives must be considered. Innovation in service delivery can include reverse flows in the supply chain where there is potential for lessons to be learned from activities and initiatives implemented elsewhere to enable the adoption of good practice in the NHS (Hinrichs et al., 2014). Public sector bodies such as the NHS are being encouraged to stimulate sustainability in the private sector by leading by example. An advantage they have is in the volume of the requirement of goods, as they can leverage their influence as major procurers of good and services (Brammer and Walker, 2011). In the Carter Review, sustainability is considered in terms of energy efficiencies, carbon footprint and food waste but this is not explicit in new procurement mandates and supplier management processes that are to evolve as a result of the review (Gov.UK, 2016). As sustainable procurement in practice and literature develops with gusto, the reverse flow of these goods back into the supply chain for various purposes demands attention. Given the aforementioned limitations on RE work on NHS devices (Xie et al., 2016), there is scope for further research in this area.

Recent investigations have shown the NHS has no standard across its trusts for the return of medical equipment, devices and apparatus. When investigating wheelchair allocation and return in Canada, Chouinard et al. (2009) found the same issue. Recently, the NHS has received negative media attention for its lack of RE inciting fury through the tabloid press who published photographs of NHS equipment such as crutches, mobility aids and limb braces in a skip destined for landfill in 2016. Some trusts have implemented initiatives to gather up unwanted items for return, showing small but promising examples. 
For instance, one Local Health Service in Devon encourages people to return NHS equipment instead of throwing it away or leaving it at a Recycling Centre by offering drop off points and collection services to ensure it gets into the right reverse chain for reissue, refurbishing or recycling (Devon County Council, 2018). In 2016 the BBC's One Show assisted with a crutch amnesty (BBC, 2016) despite their first reporting of these initiatives in 2003 (BBC News, 2003). There is even evidence of small businesses stepping in to fix the failures of the RE in the NHS, such as Terry's Zimmers, also in Devon who refurbishes and reissues mobility aids to prevent unnecessary landfill. All in all, a centralised initiative is lacking. Exploration of the challenges in the NHS of RE not being implemented and how it might be achieved is needed and investigating just one piece of equipment will help to map the issues to scale up to other apparatus. Hearing aids are issued to one person at a time for the lifespan of the product (damage or obsolescence) or for as long as the patient needs the device, making them similar to other equipment issued by the NHS that could be tracked and returned.

\subsection{Legal Statutes affecting reuse}

Despite a public sector agenda considering sustainability (Brammer and Walker, 2011), there are challenges for considering reuse in the form of legislatory requirements. There are a range of relevant legal statutes related to the return of devices in the NHS offering limited guidance. These include motions under the Medicines and Healthcare Products Regulatory Agency (MHRA) and are more specifically the Management of Medical Devices Prior to Repair, Service or Investigation DB2003(05). The Introduction to Device Bulletin: Single-use Medical Devices: Implications and Consequences of Reuse DB2006(04) discusses reuse of devices but question the benefits and advise against reuse stating: 
The reprocessing and reuse of single-use medical devices is a longstanding practice, although the MHRA advises against this. Users often justify the reprocessing of such devices on the basis of economic and environmental benefits. These perceived benefits are questionable as many of the processes required to ensure that the device is safe and fit for its intended purpose cannot be undertaken by the reprocessor (a person who undertakes the reprocessing of a medical device). Many single-use devices are also reused without adequate evaluation of the increased risks to patients.

Despite advising against reuse, in April 2015 MHRA (2015:4) published an updated version of 'Managing Medical Devices' stating in the introduction that this guidance is for those who manage reusable medical devices by stating:

The purpose of this document is to outline a systematic approach to the acquisition, deployment, maintenance (preventive maintenance and performance assurance), repair and disposal of medical devices. Guidance on medical device training is also provided. It is intended primarily for people in hospital and community based organisations that are responsible for the management of reusable medical devices, to help them set up and develop systems that promote the use of the medical devices for safe and effective health care. Many of the principles of this guidance document may apply to all medical devices.

Although in discussion of high value devices, the Department of Health note that often these cannot be reused, but this is not the case for all as there is discussion of insulin 
pumps being reconditioned and reused for other patients (DoH, 2012). However, despite the discussion of reusable medical devices in the MHRA quotation, there are no recommendations in managing suppliers in the acquisition of medical devices which will offer the potential for reuse and recycle (MHRA, 2015). Much of the advice is restricted to service, repairs and preventative maintenance as well as disposal as it is stated 'there is no legislation which specifically covers the resale or reuse of medical devices or equipment' (MHRA, 2015:49). Nonetheless, the overall goal for CLSCs is minimum wastage and maximum cost efficiencies and for the context of NHS supply chains, single use devices (SUD) for single patients is debated. For example, Hailey et al. (2008:430) find that although 'studies of variable quality suggested that SUD reuse could be safe and effective, and would give cost savings, if there were no adverse events [...] there is insufficient evidence to establish the safety, efficacy and cost-effectiveness of reusing SUDs' and hence do not support the reuse of devices designed for single use. The type of device under discussion is important though, as the reuse of needles and syringes can carry a high risk of infection compared to reuse of crutches and asthma inhalers. The MHRA in the United Kingdom does advise reuse of SUDs, but this is not consistent across Europe, Asia, Australia and North America (Popp et al., 2010).

Consequently, in considering these elements, the study investigates the area of RE and healthcare, a progressive area of research suggested by Kumar et al. (2016) and Esain et al. (2016). Practical issues with the implementation of the RE initiative are considered, a suggestion supported by Junior and Filho (2012, 2016). Specifically, there is a focus on context specific hearing aid RE, a type of study recommended by Radnor and Noke (2013). Research gaps in the literature have been identified, related to the practical reasons why RE is not occurring in the NHS beyond that the service is stretched resource- 
wise. Thus, our RQs are 1.) What are the barriers to RE for hearing aid devices in the NHS? 2.) What are the strategies for overcoming these barriers? 3.) How would a RE process be most effectively implemented for hearing aid return in the NHS?

\section{Methodology}

Radnor and Noke (2013) encourage researchers to embrace the diversity and contextual nature of public sector operations management to provide rich in-depth knowledge to understand complexity. Contextually, the uniqueness of the UK NHS is recognised but in-country healthcare studies are also very useful (eg. For Italy see Lega, Marsilio and Villa, 2013; for Quebec, Canada see Chouinard et al., 2009 and see Aptel and Pourjalali (2001) for a US/French hospital logistics comparison). Concentrating our study on one type of device (hearing aids) for RE provides insights into real facilitators and barriers to implementation. Given the already discussed limitations of RE literature (Beamon and Fernandes, 2004; Junior and Filho, 2012; Junior and Filho, 2016), this is further compounded by a private sector and RL focus specifically, and the use of mathematical modelling (Turrisi, Bruccoleri and Cannella, 2013; Batarfi, Jaber and Aljazzar, 2017). This research contributes through a qualitative, empirical study of RE.

\subsection{Dispersed nominal groups}

In order to investigate the potential for RE benefits in the NHS supply chain for medical devices, a consensus methodology which has been popular in medicine and health research since the 1960s was employed (Jones and Hunter, 1995). Qualitative consensus methodologies have their origins in grounded theory and comprehensive process analysis (Hill et al., 2005). Moving beyond typical operations and supply chain management 
(OSCM) methodologies has been recommended in order to better understand complex social and behavioural elements of OSCM (Boyer and Swink, 2008). Dispersed nominal groups (DNG) were used to obtain qualitative information from target groups most closely associated with the problem area of returning devices in the NHS (see Figure 1). Working with nominal groups is supported where there is a lack of scientific knowledge or in this case, a lack of knowledge and understanding of barriers and facilitators for RE in hearing aid supply chains (Jones and Hunter, 1995). Nominal group research is phased firstly to gather information and then identify the problem [Phase A] and secondly to discuss and develop strategies before going on to establish priorities [Phase B] (Delbecq and Van de Ven, 1971; Van de Ven and Delbecq, 1972). Although focus groups and Delphi studies are similar to this approach, the two distinct phases of using nominal groups which include feedback, idea generation and priorities, provides greater benefits to the research process (Potter et al., 2004).

\subsection{Data collection}

Semi-structured interviews were conducted by one of the research team who is experienced in this methodology and is an audiology subject expert as advocated by Fink et al., 1984 and Jones and Hunter, 1995. However, they are not expert in the subject matter of RE and were therefore able to maintain a degree of objectivity in determining the outcome or solution (Glaser, 1980). The interviews were conducted with key stakeholders involved in the hearing device supply chain from an individual to a policy level for an NHS Trust in the South of England. Audiology practice and organisation is highly similar across England due to centralised training services and hearing aid manufacturers are national, spanning the UK. See Table 1 for the roles of participants who included audiologists (and managers), hearing aid manufacturers and NHS Procurement staff 
working in small device (hearing aids) procurement. This group provided insights into the issue and management of devices, role and relationships with suppliers and the impact of NHS procurement decisions on other groups, which meant patients were beyond the scope of this research (see Figure 1). Consequently, these targeted groups of professionals are legitimate samples for research where this focuses on their expertise (Saunders and Townsend, 2016) and this recognition of expertise is a key element of the nominal group approach as part of a consensus strategy (Fink et al., 1984; Jones and Hunter, 1995). 
Figure 1 Scope of data collection reach

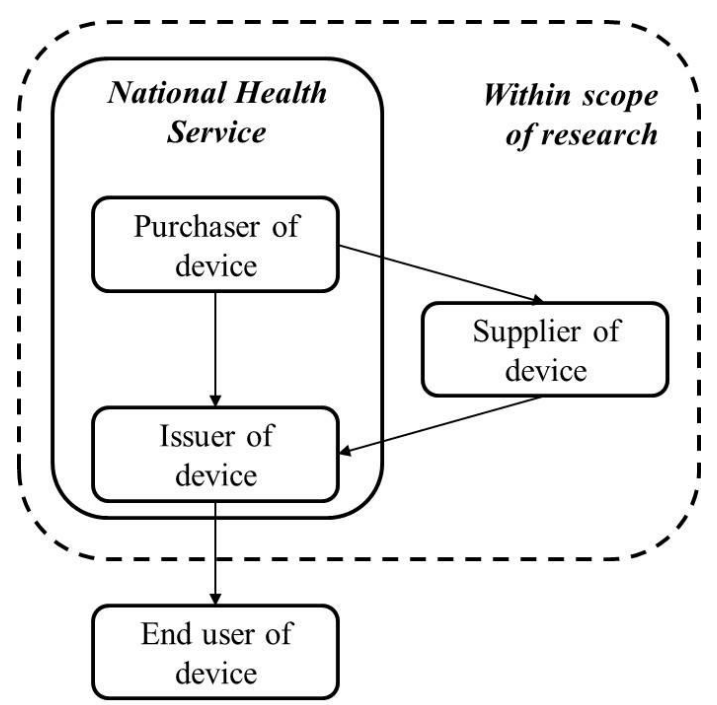

Table 1. Interviews conducted by staff role

\begin{tabular}{l|c|c}
\hline \multicolumn{1}{c|}{ Role } & $\begin{array}{c}\text { Number of } \\
\text { interviews across } 2 \\
\text { phases }\end{array}$ & $\begin{array}{c}\text { Interview code } \\
\text { (A=first phase) } \\
\text { (B=second phase) }\end{array}$ \\
\hline NHS Procurement Team & 6 & NHSP_A/NHSP_B \\
\hline Hearing Aid Manufacturers & 6 & Manf_A/Manf_B \\
\hline Audiology Managers/Audiologists & 8 & Aud_A/Aud_B \\
\hline
\end{tabular}

\subsection{Coding and Analysis}

Coding was undertaken using the first and second rounds of dispersed nominal group data and assembled under four key headings: information>barriers >solutions $>$ priorities (Delbecq and Van de Ven, 1971; Van de Ven and Delbecq, 1972; Glaser, 1980; Fink et al., 1984). The use of the dispersed nominal group approach focused on the stakeholders identified in Table 1 meaning they were able to independently input, verify data and support findings leading to the presentation of this consensus data. This process is illustrated in Table 2 and further expanded on in the findings section in Figure 2. 
Table 2. Phased coding and data analysis

\begin{tabular}{l|l|l|l}
\hline \multicolumn{1}{c|}{$\begin{array}{c}\text { Information } \\
\text { - Phase A }\end{array}$} & \multicolumn{1}{c|}{$\begin{array}{c}\text { Barriers } \\
\text { - Phase A }\end{array}$} & $\begin{array}{l}\text { Solutions/Strategies } \\
- \text { Phase B }\end{array}$ & \multicolumn{1}{c}{$\begin{array}{c}\text { Priorities } \\
\text { - Phase B }\end{array}$} \\
\hline $\begin{array}{l}\text { RE Process for } \\
\text { hearing aids (all } \\
\text { groups) }\end{array}$ & $\begin{array}{l}\text { Lack of formal } \\
\text { process. Informal } \\
\text { process between } \\
\text { Audiology and } \\
\text { Manufacturer } \\
\text { only. }\end{array}$ & $\begin{array}{l}\text { Formalised process } \\
\text { for RE including } \\
\text { procurement } \\
\text { involvement in } \\
\text { tracking and } \\
\text { refurbishment } \\
\text { potential. }\end{array}$ & $\begin{array}{l}\text { Embed RE in } \\
\text { contractual } \\
\text { requirements } \\
\text { between suppliers } \\
\text { and customers. } \\
\text { Public sector 'lead } \\
\text { by example'. }\end{array}$ \\
\hline $\begin{array}{l}\text { Cost/Economic } \\
\text { benefit }\end{array}$ & $\begin{array}{l}\text { Misalignment of } \\
\text { tender cycles. }\end{array}$ & $\begin{array}{l}\text { Positive potential } \\
\text { cost-implications of } \\
\text { RE identified. }\end{array}$ & $\begin{array}{l}\text { Incentives for } \\
\text { reuse and recycle. }\end{array}$ \\
\hline $\begin{array}{l}\text { Strategic } \\
\text { requirements }\end{array}$ & $\begin{array}{l}\text { 'Some' framework } \\
\text { requirements } \\
\text { (MHRA). }\end{array}$ & $\begin{array}{l}\text { Reuse feasible. } \\
\text { Considered as SUD } \\
\text { but they are reusable. } \\
\text { Adherence to } \\
\text { MHRA. }\end{array}$ & $\begin{array}{l}\text { Formalised } \\
\text { guidance within } \\
\text { legal statutes } \\
\text { instead of } \\
\text { ambiguity. }\end{array}$ \\
\hline Behaviours & $\begin{array}{l}\text { Not made clear to } \\
\text { users that } \\
\text { equipment belongs } \\
\text { to NHS and is } \\
\text { borrowed. }\end{array}$ & $\begin{array}{l}\text { Clarity of ownership, } \\
\text { encourage behavior } \\
\text { of return for } \\
\text { recycle/reuse. }\end{array}$ & $\begin{array}{l}\text { Formal process } \\
\text { designed to } \\
\text { capture return of } \\
\text { hearing aids. }\end{array}$ \\
\hline
\end{tabular}




\section{Findings}

The three key stakeholder groups' involvement has allowed the mapping of the RE of NHS hearing devices. The facilitators and barriers to RE of hearing aid devices which has been validated through our consensus approach are presented. Suggested implementation of the RE initiative using audiology departments as the primary leading stakeholder is presented in the schematic (Figure 2).

\subsection{Key stakeholders}

What became clear across every group was that the audiology departments were identified as the primary leading stakeholder in terms of their relationships with NHS Procurement, suppliers and having direct patient contact. This was illustrated in discussions with manufacturers and audiologists who discussed how refurbishment is carried out between audiology departments and manufacturers. Although the NHS has implemented electronic ordering systems, products which come back into the supply chain are not tracked as this bypasses NHS central systems and is arranged between audiologists and manufacturers:

"Refurbishment is done between department and manufacturer. With the new electronic ordering systems, the NHS supply chain can keep track of what is ordered by each centre but only for new devices" (NHSP_A_1).

The priority for NHS Procurement is the purchase of new devices. For a reverse flow of equipment they are not currently, nor are there any plans to be central to the process. 


\subsection{Facilitators to RE implementation}

Identification of the key roles and relationships between actors in the hearing device supply chain, enabled the identification of facilitators and barriers to RE implementation. The facilitators to implementation were illustrated by three key examples in the hearing aid supply chain which included the economics of refurbishment, strategic requirements through the feasibility of refurbishment and the consideration of social norms.

\section{Economics of refurbishment}

Participants identified that there is a cost saving for audiology departments who have systems in place to refurbish devices as they can be re-issued at approximately two thirds the cost of new. The average cost of a new hearing aid is $£ 58$ and the cost of a refurbished aid is $£ 40$. There is also a potential incentive for manufacturers where the margin on reconditioning exceeds that on new devices. Audiology staff recognised that under the current climate, refurbishment was highly viable and valuable:

\footnotetext{
"It's cheaper if we have something refurbished. There is no choice really. It's an economic imperative” (Aud_A_1).
}

\section{Strategic requirements}

There are some framework requirements for suppliers to refurbish old devices such as the Medical Device Directive to ensure there is no cross contamination through handling devices or contamination of bodily fluids. This cross contamination is usually mitigated by sterilisation but this is not suitable for hearing aids due to internal components. Suppliers confirmed that hearing aids are considered a SUD. One manufacturer gave the 
example of how customer reconditioning meant the possibility of cross contamination where apparently clean aids were found to be contaminated:

"In general terms, hearing aids are considered as single patient use, i.e. they are reusable but only after undergoing a rigorous and effective refurbishment. I can clearly confirm that even the cleanest of looking hearing aids when opened demonstrate evidence of use whether through dirt and grime or ingress of ear wax. The risk of cross contamination - although low- is there”(Manf_A_2).

Contradictory advice appears to exist however on what is feasible in terms of cleaning and recycling hearing aids. Staff referred to the role of the internet in providing information on this and how there is a lack of consistency in concluding what is best practice for those looking for advice:

\footnotetext{
"Google searches of "reuse of medical devices", "Reuse of hearing aids", and "sterilise hearing aids" all throw up interesting articles and sources of information, all provide comment, guidance, and direction - none are conclusive. It is key to distinguish guidance for the cleaning of a hearing aid for use by the same person to that for reuse by another individual” (Manf_A_1).
}

\section{Social norms}

Devices would be more likely to be returned by patients where it is accepted that hearing aids are on loan and must be returned. This reinforcement that aids are on loan, is perceived by audiologists to be welcomed by patients as they are aware of challenging 
fiscal times for health service providers. Despite these social norms, there is uncertainty as to where and if hearing aids are returned which creates challenges in determining the level of returns being received by the manufacturer:

"There is no refurbishment or recycling in the private sector as far as I am aware. Public healthcare need to lead on this with the challenge that there is no demand for it from patients at the moment. We rarely get asked what they should do with their old aids. If people became more accustomed to returning what actually belongs to the NHS this would be a driver to successful return. Equipment across the NHS is issued [temporarily] to patients, not given to them and if this message was clearer we might see better return rates" (Aud_A_4).

\subsection{Barriers to RE implementation}

Some of the facilitators can also be identified as barriers as what should happen is not necessarily current practice as the processes to support this are lacking. Barriers to the return of devices impacting this facilitation were also identified and these cover four key areas including strategic misdirection where technology and policy does not support RE, the lack of process, the lack of behavioural incentive and the pace of technological change.

1. Strategic misdirection

The NHS focus latterly on procurement has shown issues emerge over inventory management, obsolescence and a need to consolidate purchasing across healthcare trusts (Gov.UK, 2016). Currently, in managing inventory and obsolescence, the NHS is striving 
to manage efficient supply and new device issue, however, there are currently no targets for device return or reissue, except for timescales within supply chain tender specifications. The onus is on the NHS Trusts to 'schedule' aids for reconditioning and manage this, not centralised procurement, but there is recognition that further work is needed to support the provision and management of hearing devices. The purchasing power of the NHS, as one of the world's biggest spending organisations with a planned expenditure for 2016/17 of £120.611bn (NHS Confederation, 2017), could be better utilised to encourage manufacturers and suppliers to support RE. During the consensus validation, an audiologist observes:

"The information flow here is correct and goes beyond just ordering new devices. NHS Procurement need to incorporate return, refurbishment and recycling into contracts for suppliers. Audiologists can't do it alone and we certainly can't send things back with no basic processes to do so" (Aud_B_2)

As strategic requirements have been identified as facilitators to RE of hearing aids, NHS Procurement confirms that this is a current barrier to it too as it will affect procurement in terms of additional processes of tracking and refurbishment potential:

"We do need to make some substantial changes to how hearing aids are provided but I don't know what effect this will have on procurement because of tracking, costs and refurbishment potential. It all really needs to be driven by procurement" (Aud_A_4). 
This uncertainty looks set to continue as although the Carter Review (Gov.UK, 2016) has identified the importance of sustainable practices in the NHS, this has been discussed in generalist terms and has not provided specific illustrations in terms of medical devices and how these will be managed in the scope of procurement. Currently RE processes in hearing devices are not considered in the procurement process of medical devices by the NHS centrally and there was no indication that this was to change as the procurement mandate was for supply and use of new devices:

"We don't get involved in reverse logistics [...] our mandate is to ensure the efficient supply and use of new devices" (NHSP_A_2).

Moreover, suppliers provide evidence that it is not part of their strategy either:

"We recycle based on practicality coupled with expense. So if there is no business sense to outlay more on the recovery than is viable for value, we won't [...] Plastics and rubber parts are not recycled. This is down to cost but also on the risk of cross-contamination. With any medical device cross-contamination is a key factor, depending upon the make-up of the device it may limit the extent of cleaning and sterilisation which will impact what can be recycled for what purpose"(Manf_A_3)

They confirm this in the consensus validation that a green agenda is lacking when it comes to devices: 
"My opinion on the medical device itself is that there is not a green agenda. There is on the supply chain, packaging, information, stocks and even processes but not on the actual device itself. The focus there is functionality, meeting customer need, and compliance with regulatory requirements" (Manf_B_3).

\section{Lack of Process}

Within the NHS, control of medical devices lies with the provider but when this device is issued to the patient at the clinic, the control is handed over to the patient for the duration of use of the device. The provider regains control at the end of the life of the device, for example when the device should be returned. Commonly, this is not made explicit to the patient and so patients are often issued with new devices, with previous versions still in their possession:

"Patients are not incentivised to return the device for replacement, maintenance, repair or proper disposal" (Aud_A_1).

Consequently, this means there is no formal process or mechanism for capturing patients who return devices, either through clinical appointments or even in attendance at their general practitioner at a later date:

"There are tracking issues [...] individual serial numbers are not tracked and linked to patients when it comes to refurbishment" (Aud_A_4). 


\section{Lack of behavioural incentive}

Despite clear community incentives that patients were familiar with in terms of expected behaviours in managing household wastes and the disposal of electronic devices, hearing aids were not considered in this manner. The lack of tracking process identified previously, means that the need to return the device is not explicit and therefore, patients are not incentivised to return devices for reconditioning or proper disposal:

"Patients don't hand back the original hearing aid when they have a new one fitted and this has not always been encouraged" (Aud_A_2).

The potential of psychological utility is not being exploited. To date, it was evident from the participants in this study that there is a lack of pressure on the NHS to foster RE from the public, also an observation made by Esain et al. (2016).

\section{Pace of technological change}

Part of the challenge in managing current device usage and inventories is the risk of obsolescence due to the pace of technological change and the wide variety of products available for use. This is fueled by the misalignment of the tender and reconditioning cycles which means the reconditioned aids can be at risk of obsolescence:

"The tender cycle operates over a shorter period than the reconditioning cycle to incorporate advances in technology. This means reconditioned aids become obsolete"(Manf_A_2). 
This poses a risk to the key facilitator of cost incentive of reissue which has been identified. However, other benefits of RE can be realised through recycling, for example, even if technological change has rendered the device obsolete. 


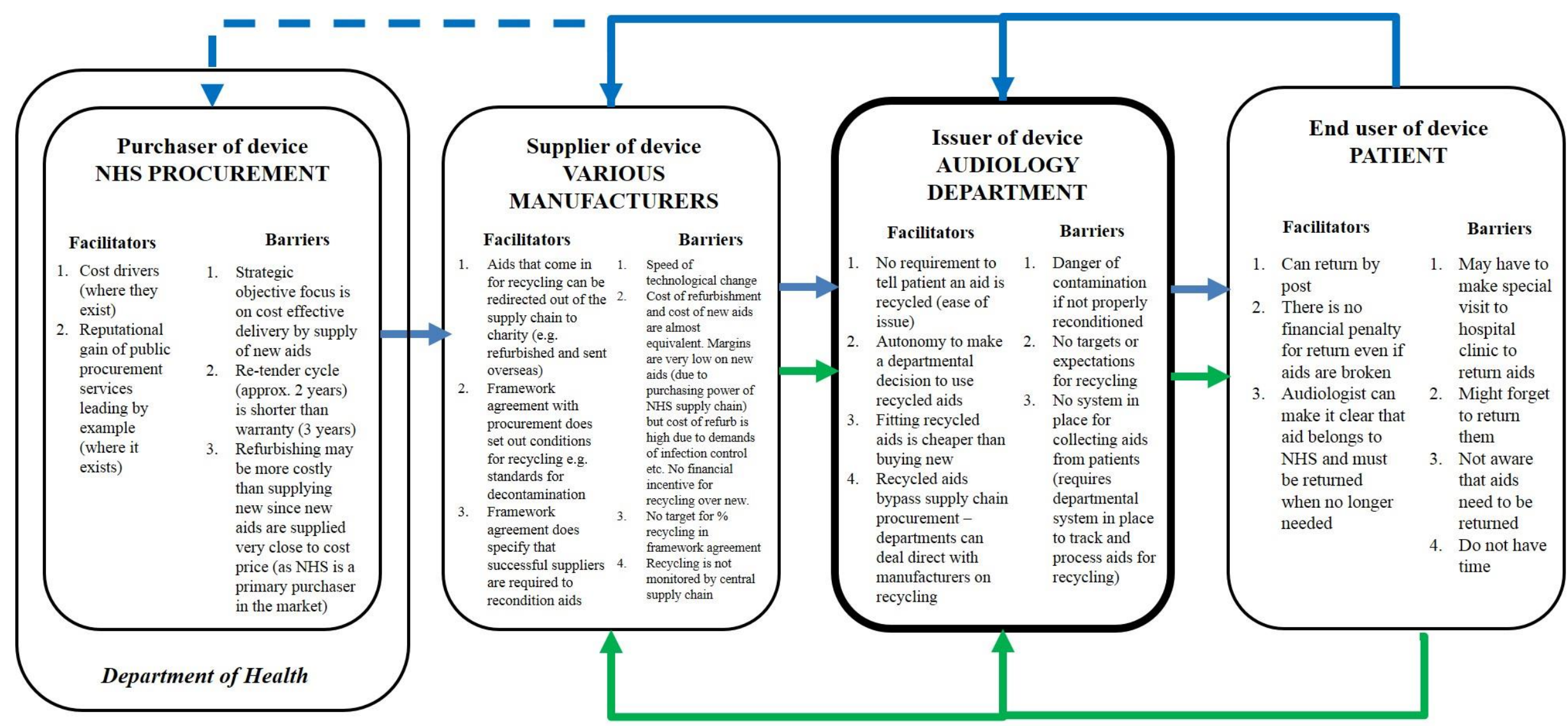

$\longrightarrow$ Information flow

$\rightarrow$ Materials flow

Figure 2. Framework for RE of hearing aids in NHS 


\section{Discussion}

Brammer and Walker (2011) identified cost as the main barrier to public sustainable procurement and top management buy-in as the main facilitator. Our study on RE in healthcare shows cost as one of the reasons both for and against the return on devices depending on the stakeholder and the audiology department (and manager of this department) are identified as a key player in the implementation of RE where NHS Procurement has a reduced role in the purchase and no role in the return of the devices. There is currently a blend of autonomy between NHS Procurement and audiology departments. For example, NHS Procurement are tasked with new purchases where they can achieve advantages of centralisation such as quantity discounts (Crama, Pascual and Torres, 2004), reduced duplication of effort, economics of scale and economics of scope. However, the current recommendations for the centralisation of procurement services and associated supplier contracts in the Carter Review means that going forward, this will be a challenge to currently held audiology autonomy (Gov.UK, 2016). Even recent discussions over Sustainability and Transformation Plans (STPs) in the NHS do not focus on centralised services, giving Trusts localised powers (NHS England, 2017).

\subsection{Barriers to RE for hearing aid devices in the NHS}

The barriers to RE for hearing aid devices in the NHS (RQ1) are categorised as strategic misdirection, lack of process, lack of behavioural incentive and pace of technological change. Figure 2 presents these in more detail for each stakeholder. It also shows the materials flow from suppliers to audiology departments to patients and back again through audiology departments to suppliers. Although the extent that this is occurring is patchy due to the barriers. The information flow is similar except that NHS Procurement are best placed to encourage suppliers to remanufacture hearing aids which could be done through supplier development 
programmes (Zhang, Pawar and Bhardwaj, 2017). Additionally, information should be transferred back up the chain to NHS Procurement for target setting and management of the reverse flow of the devices. The NHS could be realising the potential of innovative business models in the reverse supply chain, by looking beyond simply returning to the point of origin (Beh et al. 2016). The Department of Health as a wider context actor also has a part to play in this strategic pressure.

\subsection{Strategies for overcoming barriers}

To implement RE for hearing aid devices, strategies for overcoming the barriers are identified (RQ2). Firstly the mix of responsibility should be utilised for power advantages over local requirements. A blend of centralised and decentralised operations is often advantageous (Munson, 2007). Secondly, procurement should take more of a direct role in formulating return policies into contracts. For example, as NHS Procurement has purchasing power in the supply chain, they may add value through the enforcement of requirements to RE through formal contracts, whereby the audiology department will operationally run the process. There has been some debate on what kind of contracts best support supply chain coordination in the scope of reverse flow items (Govindan, Popiuc and Diabat, 2013) but that they do play a positive role (Guo et al. 2017). Thirdly, strong strategic messages from the senior management and official channels for how to implement initiatives in healthcare are needed (Böhme et al., 2016). 


\subsection{RE process implementation}

Audiologists and manufacturers should design a suitable process for the RE even though there is conflicting information on the extent to the refurbishment allowed (RQ3). Audiologists need to play a role in explaining to patients that the aids are on loan and withholding new allocations. The patients are immersed in the device issue processes due to their often active participation and providers need to set up different procedures to manage the returns of customer items, according to the process phase when the return occurs, such as refit on the basis of a previous return (Kumar et al., 2016). Our behavioural findings of patients' motivation to return, while secondary, can be attributed to consumer motivation towards RE such as Yuan et al.'s (2016) study in the electronics industry. As customer non-compliance is not a primary cause of reverse systems breakdowns (Breen, 2006) the change in behaviour needed is important but the process infrastructure needs to be resolved first. The NHS does not have the issue of 'upsetting' patients and risk losing trade by asking for their equipment back as could be the case in the private sector (Breen, 2006), so the context is unique. There is a wider debate to be had here - for example, there is research to suggest that patients would accept medicines that were still in their packaging and hence considered suitable for reuse, if they were displaced from pharmacy stock, or returned from a patient (Alhamad, Patel and Donyai, 2018). We have not directly researched the patient voice and thus not concluded on patient views on reusing hearing aids, but instead considered the barriers to return of the devices. Thus there is scope for more work to be conducted on whether patients would use reconditioned hearing aids of the NHS did this. Additionally, whether the patient would be told that they had been repaired and reconditioned or whether they would be distributed to them as new without their knowledge would need to be considered. Moreover, whether they would need to know should be investigated. The public 
sector potentially have the starting position of a true circular economy perspective based on whether a choice should be given.

Networked systems will be required for data management of hearing aid allocation (Ferguson and Browne, 2001). Evidence suggests that when innovative and suitable tools support the proper management of the information and material reverse flow, legislation is satisfied and improvements in supply chain performance are achieved (Turrisi, Bruccoleri and Cannella, 2013). Legislation is ambiguous on reusing SUDs because the MHRA advises against, rather than forbids it, thus legislation has failed to keep up with technological advances. MHRA is based on EU directives from the 1990s and 2000s. In 2012 the European Commission proposed new Regulations ([EU] 2017/745 and [EU] 2017/746) but these were only formally adopted on $5^{\text {th }}$ April 2017 and will apply after a transition period of three and five years respectively. (EU) 2017/745, section 38 notes that reprocessing of SUDs should only be conducted where permitted by national law and also by the manufacturer, but later supports that member states can allow reprocessing by health institutions as long as the safety and performance levels are equivalent to the original SUD (European Commission, 2017).

Where refurbishment cannot occur, recycling should be managed. NHS Procurement and patient behaviour have supporting roles compared to the autonomy of the audiologist to effectively carry out RE. The evidence shows that suppliers are reluctant with no incentive to employ RE and need the encouragement from all three groups to act. Figure 2 shows that the end user behaviour of returning the device, and the NHS Procurement requirement for manufacturers to do so are only superficial reasons for the lack of RE. Actually, the audiology departments who have autonomy to design these processes are where the focus for RE 
implementation should be directed. It is not uncommon in the private sector that drivers for reverse benefits are driven at 'firm' level rather than supply chain level (Masi et al., 2018).

There is not a closed loop between the patient, audiology department, hearing aid manufacturer and NHS Procurement for hearing aid recycling or reuse, nor does there need to be to get RE initiated. Although purchasing of new aids is performed via NHS Procurement, and they set out some standards for decontamination and turnaround time for recycling and refurbishment, the process is actually negotiated directly between individual departments and hearing aid manufacturers. This looks set to continue with the localised approach of STPs (NHS England, 2017). Thus, NHS Procurement may have a powerful overarching opportunity to specify requirements to suppliers nationally which would be useful, but the audiology departments have the autonomy for negotiation and process design at the local level meaning implementation and success is more likely.

\section{Conclusion}

As our health care systems continue to struggle with increasing demands for their services and many organisations are looking for ways in which to improve the design of their systems and work more effectively across the health care economy (Wikner, 2017), the focus of this study is the reverse flow of the supply chain. The barriers to RE for hearing aids in the UK are identified and a suggested framework for implementation of RE of the devices using key players is presented. The study has specifically focused on issues with the practical implementation of a RE process and directly employs those NHS practioners dispensing the devices. The resultant process has been identified as most effective due to the facilitating nature of the audiology department between the end user and manufacturer, with the centralised NHS 
Procurement team assisting with better enforcement and incentives for manufacturer cooperation. To achieve initiatives such as this, there is a need to apply integrated SCM practices in NHS Procurement (Sanderson et al., 2015) and for increased interdisciplinary work across health-care management and SCM (Hinrichs et al., 2014).

This research seeks to raise the profile of RE in the NHS devices supply chain, focusing on potential financial outcome and sustainability. The framework provides a positive step towards a reverse supply chain with minimum wastage and maximum cost efficiencies for device return in the NHS. Identifying barriers and suggesting ways to overcome these makes the framework ready for empirical testing. Our proposals support discussion by Radnor and Noke (2013) who highlight that although private sector practices are transferred into the public sector, adaptability is key as is consideration of ownership and value. This is evident in this work through the adaptation of RE device supply chains, rather than endorsing a CLSC. Adaptation allows focus on the social practices of ownership of RE processes where audiologists are identified as a key stakeholder in currently facilitating this and the value of RE processes to be initially identified and established by centralised NHS Procurement which will support overarching sustainability policies.

\section{Limitations and future research}

The study extends the literature beyond the manufacturing derived RE concept to develop an understanding of the NHS, supplier and patient role in preserving and co-creating value in RE in UK healthcare. This study has focused on the hearing aid supply chain which may not be representative of other device supply chains in the NHS. It is appreciated that the disposal of hearing aids, being so small, has a relatively minor impact on landfill masses. However, the 
process management of the issue of the device is illustrative of other medical equipment and further investigation into manufacturer-led initiatives and provider-led initiatives should be conducted to devise the most effect strategies and motivations for the change in process (Guo et al., 2017; Batista et al., 2018). The mapping developed represents only the first step in investigating the NHS supply chain and any interventions based on it will need to be tested and validated. However, there is scope for further research in this area and there is potential for the mapping to be applied to other devices once the process is tested. The contextual nature of the NHS is recognised, including the importance of cost efficiencies and behavioural implications on the value of 'free' and support similar studies carried out in other country healthcare provision.

\section{Acknowledgements}

The authors would like to thank the Researcher Development Programme Fund offered by the University of Surrey and the International Centre for Management and Governance Research (ICMGR) 'Summer Scholars Programme' at Edinburgh Napier University, both of which funded travel grants for the authors, thus supporting this collaborative project across institutions. 


\section{References}

Abdallah, T., Diabat, A. and Simchi-Levi, D. 2012. "Sustainable supply chain design: a closed-loop formulation and sensitivity analysis". Production Planning \& Control 23 (2-3): 120-133.

Action on Hearing Loss. 2016. NHS hearing aid services are under threat. https://www.actiononhearingloss.org.uk/hearingaidcuts.aspx

Alhamad, H., Patel, N. and Donyai, P. (2018). "How do people conceptualise the reuse of medicines? An interview study". International Journal of Pharmacy Practice 26 (3): 232-241.

Aptel, O. and Pourjalali, H. 2001. "Improving Activities and Decreasing Costs of Logistics in Hospitals. A Comparison of U.S. and French Hospitals". The International Journal of Accounting 36: 65-90.

Baffo, I., Confessore, G., Liotta, G. and Stecca, G. 2009. “A Cooperative Model to Improve Hospital Equipments and Drugs Management", in Camarinha-Matos L.M., Paraskakis I., and Afsarmanesh H. (Ed.) Leveraging Knowledge for Innovation in Collaborative Networks, Springer, Portugal, 43-50.

Batarfi, R., Jaber, M. Y. and Aljazzar, S. M. 2017. "A profit maximization for a reverse logistics dualchannel supply chain with a return policy”. Computers \& Industrial Engineering 106: 58-82.

Batista, L., Bourlakis, M., Smart, P., \& Maull, R. 2018. "In search of a circular supply chain archetype-a content-analysis-based literature review". Production Planning \& Control 29 (6): 438451.

BBC. 2016. Crutch amnesty. http://www.bbc.co.uk/programmes/p04hnw91

BBC News. 2003. Crutch amnesty announced. http://news.bbc.co.uk/1/hi/england/west_midlands/3187239.stm

Beamon, B.M. and Fernandes, C. 2004. "Supply-chain network configuration for product recovery". Production Planning \& Control 15 (3): 270-281.

Beh, L.S., Ghobadian, A., He, Q., Gallear, D. and O'Regan, N. 2016. "Second-life retailing: a reverse supply chain perspective". Supply Chain Management: An International Journal 21 (2): 259-272.

Böhme, T., Williams, S. J., Childerhouse, P., Deakins, E. and Towill, D. 2016. "Causes, effects and mitigation of unreliable healthcare supplies". Production Planning \& Control 27 (4): 249-262.

Boyer, K.K, Swink, M.. 2006. "Empirical Elephants - Why Multiple Methods are Essential to Quality Research in Operations and Supply Chain Management". Journal of Operations Management 26: 337-348.

Brammer, S. and Walker, H. 2011. "Sustainable procurement in the public sector: an international comparative study". International Journal of Operations \& Production Management 31 (4): $452-$ 476.

Breen, L. 2006. "Give me back my empties or else! - A Preliminary analysis of customer compliance in reverse logistics practices (UK)", Management Research News, 29 (9): 532-551

Breen, L., Xie, Y. and Cherrett, T. 2016. "Where are you? A preliminary examination of the track and trace mechanisms in place to facilitate effective closed-loop medical equipment retrieval in the National Health Service (NHS)(UK). British Academy of Management Conference, Newcastle.

Campbell, D. 2015. NHS accused of cruel rationing of hearing aids. The Guardian. https://www.theguardian.com/society/2015/jan/03/hearing-aids-supply-cuts-nhs-depressiondementia

Carter, C.R. and Ellram, L.M. 1998. "Reverse logistics: a review of the literature and framework for future investigation". Journal of Business Logistics 19 (1): 85.

Chan F.T.S. and Chan H.K. 2008. "A survey on reverse logistics system of mobile phone industry in Hong Kong”. Management Decision 46 (5): 702-708.

Chouinard, M., Ait-Kadi, D., Van Wassenhove, L. and D'Amours, S. 2009. “Conceptual framework for the design and management of value loops-application to a wheelchair allocation context". Production Planning and Control 20 (8): 703-723.

Crama, Y., Pascual, J. and Torres, A. 2004. "Optimal procurement decisions in the presence of total quantity discounts and alternative product recipes". European Journal of Operational Research 159 (2): 364-378.

Defee, C.C., Esper, T. and Mollenkopf, D. 2009. Leveraging closed-loop orientation and leadership for environmental sustainability. Supply Chain Management: An International Journal 14 (2): $87-$ 98. 
DEFRA (Department of Environment, Food and Rural Affairs). 2007. Securing the future: UK Government Sustainable Procurement Action Plan Incorporating the Government response to the report of the Sustainable Procurement Task Force. London: DEFRA.

Delbecq A. and Van de Ven, A. 1971. "A group process model for problem identification and program planning”. Journal of Applied Behavioral Science 7: 467-492.

Devon County Council. 2018. NHS equipment returns. https://new.devon.gov.uk/wasteandrecycling/recycling-centres/nhs-equipment/

DoH (Department of Health). 2012. High cost devices. https://www.gov.uk/government/news/highcost-devices--2

Dunn, P., McKenna, H. and Murray, R. 2016. Deficits in the NHS 2016. The King's Fund Briefing. https://www.kingsfund.org.uk/sites/files/kf/field/field_publication_file/Deficits_in_the_NHS_King s_Fund_July_2016_1.pdf

Esain, A., Aitken, J., Williams, S. and Kumar, M. 2016. "Reverse exchange: Classifications for public service SCM”. Supply Chain Management: An International Journal 21 (2): 216-227.

European Commission. 2017. The new Regulations on medical devices.

https://ec.europa.eu/growth/sectors/medical-devices/regulatory-framework_en

Ferguson, N. and Browne, J. 2001. "Issues in end-of-life product recovery and reverse logistics". Production Planning \& Control 12 (5): 534-547.

Fink, A., Kosecoff, J., Chassin, M. and Brook, R.H. 1984. "Consensus methods: characteristics and guidelines for use". American Journal of Public Health. 74 (9): 979-983.

Glaser, E.M, (1980). "Using behavioral science strategies for defining the state-of the-art". Journal of Applied Behavorial Sciences 16: 79-92.

Gov.UK, 2016. The Carter Review - Productivity in NHS hospitals.

https://www.gov.uk/government/publications/productivity-in-nhs-hospitals

Govindan, K., Popiuc, M. N. and Diabat, A. 2013. "Overview of coordination contracts within forward and reverse supply chains". Journal of Cleaner Production 47: 319-334.

Govindan, K., Soleimani, H. and Kannan, D. 2015. "Reverse logistics and closed-loop supply chain: A comprehensive review to explore the future". European Journal of Operational Research 240 (3): 603-626.

Guo, S., Shen, B., Choi, T. M. and Jung, S. 2017. "A review on supply chain contracts in reverse logistics: Supply chain structures and channel leaderships”. Journal of Cleaner Production 144: 387-402.

Hailey, D., Jacobs, P.D., Ries, N.M. and Polisena, J. 2008. "Reuse of single use medical devices in Canada: clinical and economic outcomes, legal and ethical issues, and current hospital practice". International Journal of Technology Assessment in Health Care 24 (04): 430-436.

Hill, C.E., Knox, S., Thompson, B.J., Williams, E.N., Hess, S.A. and Ladany, N. 2005. "Consensual Qualitative Research: An Update”. Journal of Counseling Psychology 52 (2): 196-205.

Hinrichs, S. Jahagirdar, D. Miani, C. Guerin, B. and Nolte, E. 2014. "Learning for the NHS on procurement and supply chain management: a rapid evidence assessment. Health Technology Assessment 2 (55).

International Longevity Centre UK. (2014). Commission on Hearing Loss: Final Report. http://www.ilcuk.org.uk/images/uploads/publication-pdfs/Hearing_loss_Commission_final_report_website.pdf

Jones, J. and Hunter, D. 1995. Qualitative research: consensus methods for medical and health services research. British Medical Journal 311 (7001): 376-380.

Junior, M.L. and Filho, M.G. 2012. "Production planning and control for remanufacturing: literature review and analysis". Production Planning \& Control 23 (6): 419-435.

Junior, M.L. and Filho, M.G. 2016. "Production planning and control for remanufacturing: exploring characteristics and difficulties with case studies". Production Planning \& Control 27 (3): 212-225.

Klein, R. 2013. The New Politics of the NHS (7th ed.). London: Radcliffe Publishing Ltd.

Knapton, S. 2016. Rationing of NHS hearing aids may fuel dementia epidemic. The Telegraph. http://www.telegraph.co.uk/news/science/science-news/12156671/Rationing-of-NHS-hearing-aidsmay-fuel-dementia-epidemic.html 
Kumar, V., Amorim, M., Bhattacharya, A. and Garza-Reyes, J.A. 2016. "Managing reverse exchanges in service supply chains". Supply Chain Management: An International Journal 21 (2): $157-165$.

Larsen, S. B., Masi, D., Jacobsen, P. and Godsell, J. 2018. "How the reverse supply chain contributes to a firm's competitive strategy: a strategic alignment perspective". Production Planning \& Control, 29 (6): 452-463.

Lega, F, Marsilio, M and Villa, S. 2013. "An evaluation framework for measuring supply chain performance in the public healthcare sector: evidence from the Italian NHS". Production Planning \& Control 24 (10-11): 931-947.

Li X. and Olorunniwo F. 2008. "An exploration of reverse logistics practices in three companies". Supply Chain Management: An International Journal 13 (5): 381-386.

Limbcare. 2017. http://www.limbcare.org/

Masi, D., Kumar, V., Garza-Reyes, J.A. and Godsell, J. 2018. "Towards a more circular economy: exploring the awareness, practices, and barriers from a focal firm perspective". Production Planning \& Control 29 (6): 539-550.

Monitor. 2015. NHS adult hearing services in England: exploring how choice is working for patients. https://www.gov.uk/government/uploads/system/uploads/attachment_data/file/409273/Adult_hearin g_services_-_Monitor_s_report.pdf

MHRA (Medicines and Healthcare products Regulatory Agency). 2015. Managing medical devices: Guidance for healthcare and social services organisations. http://www.idscuk.co.uk/docs2015/Managing_medical_devices_-_Apr_2015.pdf

Munson, C.L. 2007. "The appeal of partially centralised purchasing policies". International Journal of Procurement Management 1 (1-2): 117-143.

National Audit Office. 2013. Sustainable procurement in government: A briefing for the House of Commons environmental audit select committee.

http://www.unpcdc.org/media/414878/eac_briefing_sustainable_procurement_government.pdf

NHS Commissioning Board. 2012. Procurement of healthcare (clinical) services. Briefing 1: How does procurement fit with the different stages of commissioning? https://www.england.nhs.uk/wpcontent/uploads/2012/09/procure-brief-1.pdf

NHS Confederation. 2017. Key statistics on the NHS. http://www.nhsconfed.org/resources/keystatistics-on-the-nhs

NHS England. 2011. NHS Atlas of Variation. http://www.rightcare.nhs.uk/atlas/downloads/Hearing_AoV_2011.pdf

NHS England. 2016. New system for buying and supplying high-cost medical devices in specialised services. https://www.england.nhs.uk/commissioning/spec-services/key-docs/medical-devices/

NHS England. 2017. Sustainability and Transformation Plans (STPs). https://www.england.nhs.uk/stps/

Popp, W., Rasslan, O., Unahalekhaka, A., Brenner, P., Fischnaller, E., Fathy, M., Goldman, C. and Gillespie, E. 2010. "What is the use? An international look at reuse of single-use medical devices". International Journal of Hygiene and Environmental Health 213: 302-307.

Potter, M., Gordon, S. and Hamer, P. 2004. "The Nominal Group Technique: A useful consensus methodology in physiotherapy research". NZ Journal of Physiotherapy 32 (2): 70-74.

Procuring the Future. 2006. Sustainable Procurement National Action Plan: Recommendations from the Sustainable Procurement Task Force.

https://www.gov.uk/government/uploads/system/uploads/attachment_data/file/69417/pb11710procuring-the-future-060607.pdf

Radnor, Z. J. and Noke, H. 2013. "Conceptualising and contextualising public sector operations management". Production Planning \& Control. 24 (10-11): 867-876.

Ritchie, L., Burnes, B., Whittle, P. and Hey, R. 2000. "The benefits of reverse logistics: the case of the Manchester Royal Infirmary Pharmacy". Supply Chain Management: An International Journal 5 (5): 226-234.

Rogers D.S. and Tibben-Lembke, R.S. 1999. Going Backwards: reverse logistics trends and practices. Reverse Logistics Executive Council: Pittsburgh, PA 
Sanderson, J., Lonsdale, C., Mannion, R. and Matharu, T. 2015. "Towards a framework for enhancing procurement and supply chain management practice in the NHS: Lessons for managers and clinicians from a synthesis of the theoretical and empirical literature". Health Services and Delivery Research 3 (18).

Saunders, M.N. and Townsend, K. 2016. "Reporting and justifying the number of interview participants in organization and workplace research. British Journal of Management 27 (4): 836852.

Schenkel, M., Caniëls, M. C., Krikke, H. and van der Laan, E. 2015. "Understanding value creation in closed loop supply chains-Past findings and future directions". Journal of Manufacturing Systems 37: 729-745.

Shaharudin, M. R., Govindan, K., Zailani, S., Tan, K. C. and Iranmanesh, M. 2017. "Product return management: Linking product returns, closed-loop supply chain activities and the effectiveness of the reverse supply chains". Journal of Cleaner Production 149, 1144-1156.

Thierry, M., 1995. "Strategic issues in product recovery management". California Management Review. 37 (2): 114-135.

Turrisi, M., Bruccoleri, M. and Cannella, S. 2013. "Impact of reverse logistics on supply chain performance". International Journal of Physical Distribution \& Logistics Management 43 (7): 564585.

Van de Ven, A. and Delbecq A. 1972. "The nominal group as a research instrument for exploratory health studies". American Journal of Public Health 62 (3): 337-342.

WHO (World Health Organisation). 2017. Deafness and Hearing Loss. http://www.who.int/mediacentre/factsheets/fs300/en/

Wikner, J., Yang, B., Yang, Y. and Williams, S.J. 2017. "Decoupling thinking in service operations: a case in healthcare delivery system design". Production Planning \& Control 1-11.

Xie, Y. and Breen, L. 2012. "Greening community pharmaceutical supply chain in UK: a cross boundary approach". Supply Chain Management: An International Journal 17 (1): 40-53.

Xie, Y. and Breen, L. 2014. "Who cares wins? A comparative analysis of pharmaceutical and battery reverse logistics systems - the case of the NHS (UK)". Supply Chain Management: An International Journal. 19 (4): 455-474.

Xie, Y., Breen, L., Cherrett, T., Zheng, D. and Allen, C.J. 2016. "An exploratory study of reverse exchange systems used for medical devices in the UK National Health Service (NHS)”. Supply Chain Management: An International Journal. 21 (2): 194-215.

Yuan, R., Liu, M. J., Chong, A. Y. L. and Tan, K. H. 2016. "An empirical analysis of consumer motivation towards reverse exchange". Supply Chain Management: An International Journal. 21 (2): 180-193.

Yusuf, Y. Y., Olaberinjo, A. E., Papadopoulos, T., Gunasekaran, A., Subramanian, N. and Sharifi, H. 2017. "Returnable transport packaging in developing countries: drivers, barriers and business performance". Production Planning \& Control 28 (6-8): 629-658.

Zhang, M., Pawar, K. S. and Bhardwaj, S. 2017. "Improving supply chain social responsibility through supplier development”. Production Planning \& Control 28 (6-8): 500-511. 